\title{
ОСОБЕННОСТИ ФУНКЦИОНАЛЬНОГО СОСТОЯНИЯ ЭРИТРОЦИТОВ В УСЛОВИЯХ ГИПОКСИИ СМЕШАННОГО ГЕНЕЗА ПРИ ПОЛИТРАВМЕ
}

\author{
Матвеенко Мария Сергеевна, \\ ассистент кафедры хирургических болезней, оперативной хирургии и топографической \\ анатомии. Харьковский национальный университет имени В. Н. Каразина, Харьков, Украина, \\ ORCID ID: https://orcid.org/0000-0002-0388-138X
}

\begin{abstract}
Баранова Наденда Викторовна, к.мед.н., ассистент кафедры медииины неотложных состояний, анестезиологии и интенсивной терапии. Харьковский национальный медицинский университет, Харьков, Украина, ORCID ID: https://orcid.org/0000-0002-2991-0898
\end{abstract}

\section{Бойко Елена Владимировна,} ассистент кафедры медицины неотложных состояний, анестезиологии и интенсивной терапии. Харьковский национальный медицинский университет, Харьков, Украина, ORCID ID: https://orcid.org/0000-0003-0697-6357

\begin{abstract}
Арора Сукеи, ассистент кафедры хирургических болезней, оперативной хирургии и топографической анатомии. Харьковский нацииональный университет имени В. Н. Каразина, Харьков, Украина, ORCID ID: https://orcid.org/0000-0001-5489-7747
\end{abstract}

DOI: https://doi.org/10.31435/rsglobal_ws/30062020/7111

\section{ARTICLE INFO}

Received: 20 April 2020

Accepted: 19 June 2020

Published: 30 June 2020

\section{KEYWORDS}

traumatic disease,

lactate, pyruvate,

2.3-diphosphoglyceric acid,

ATP,

red blood cell,

metabolism.

\begin{abstract}
The question of the changes in red blood cells metabolism markers based on the pathogenetic features the course of traumatic disease in polytrauma remains open and relevant. Objective of this study was to evaluate changes in the functional state of red blood cells during hypoxia in patients with traumatic disease. A prospective randomized controlled clinical trial was carried out on 120 patients on the basis of the Polytrauma department. The main markers of the functional state of red blood cells (lactate, pyruvate, 2.3-diphosphoglyceric acid, ATP) were determined by spectrophotometric method. We have revealed that the course of the acute and early periods of traumatic disease is accompanied by changes in the functional state of red blood cells. This is evidenced by a decrease in ATP level and an increase in the levels of lactate, 2,3-DFH and lactate/pyruvate index. We have established a relationship between the markers of the functional state of red blood cells at the time of admission and the development of infectious complications, posthemorrhagic anemia, posttraumatic nephropathy.
\end{abstract}

Citation: Matvieienko Mariia, Baranova Nadiia, Boiko Olena, Arora Sukesh. (2020) Features of the Functional State of Red Blood Cells During Hypoxia in Patients with Polytrauma. World Science. 6(58), Vol.2. doi: 10.31435/rsglobal_ws/30062020/7111

Copyright: (C) 2020 Matvieienko Mariia, Baranova Nadiia, Boiko Olena, Arora Sukesh. This is an open-access article distributed under the terms of the Creative Commons Attribution License (CC BY). The use, distribution or reproduction in other forums is permitted, provided the original author(s) or licensor are credited and that the original publication in this journal is cited, in accordance with accepted academic practice. No use, distribution or reproduction is permitted which does not comply with these terms.

Введение. Основными осложнениями сочетанной травмы является пневмония (10,9\%$20 \%)[1,2,3]$, местные гнойные осложнения (13\%) инфекции мочевыводящих путей $(4,7-6 \%)$ $[4,5]$, острый респираторный дистресс синдром $(4,4 \%)$, постгеморрагическая анемия $(16 \%)$, 
полиорганная недостаточность, сепсис $(1,5 \%)[4,6,7]$, тромбоэмболические осложнения $(6 \%)$ [5]. Тромбогеморрагические осложнения при политравме достигают 90\%, частота возникновения тромбоза глубоких вен нижних конечностей составляет 60-90\% [6]. Наибольшее число осложнений развивается в раннем периоде травматической болезни (ТБ) при политравме на фоне изменений, связанных с шоком, интоксикацией и гипоксией $[2,4,6]$.

Дыхательная, циркуляторная, гемическая и тканевая гипоксии приводят к нарушению процессов окислительного фосфорилирования, развитию гипоэргоза клеток, активации анаэробного пути энергообеспечения, расстройствам нормального метаболизма тканей $[8,9$, 10], на молекулярном уровне активируются биохимические каскады воспаления и апоптоза, что приводит к повреждению и смерти клеток $[10,11]$.

Изучение углеводного обмена показало, что гипоксия приводит к сдвигу в сторону анаэробного гликолиза, энергетически невыгодно для тканей. В плазме крови обнаружено резкое повышение лактата (более чем в два раза по сравнению с контролем) и пирувата - на $77 \%$. В соотношении лактат / пируват отмечается сдвиг в сторону преобладания лактата (на $20 \%$ ), что расценивается как признак метаболического ацидоза крови $[8,11,12]$.

Особую роль играет механизм компенсации гипоксии, связанный с улучшением отдачи кислорода кровью в тканевых капиллярах. Этот механизм заключается в снижении сродства гемоглобина к кислороду (смещении кривой диссоциации оксигемоглобина вправо) и является эффективным способом компенсации вторичной тканевой гипоксии, не требует затрат энергии $[10,11,13]$. Универсальным механизмом адаптации к гипоксии является активация анаэробного окисления глюкозы в эритроцитах и повышение содержания 2,3-дифосфоглицерата (2,3ДФГ) - аллостерического регулятора сродства гемоглобина к кислороду $[14,15]$. Функция транспорта кислорода гемоглобином связана с уровнем 2,3-ДФГ.

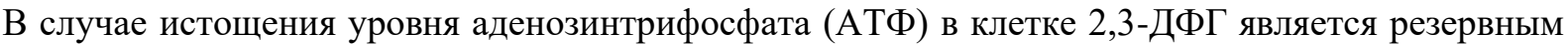
источником данного макроэргического соединения [16]. Кроме того, необходимо учитывать, что изменение содержания органических фосфатов в клетке вызывает целый ряд структурных перестроек эритроцитарных мембран [14, 15].

Динамическое наблюдение за уровнем лактата и пирувата позволяет оценить адекватность медикаментозной терапии и является прогностическим критерием в частности для пациентов с политравмой [12]. Концентрация 2,3-ДФГ и АТФ могут отражать уровень компенсаторно-адаптационных механизмов системы транспорта кислорода и энергетического обмена $[15,17]$. Однако в современной литературе вопросы изучения изменений маркеров метаболизма эритроцитов, их связь с развитием вероятных осложнений недостаточно освящены и являются необходимыми исходя из патогенетических особенностей течения ТБ при политравме.

Целью данного исследования явилось изучение функционального состояния эритроцитов в условиях развития гипоксии смешанного генеза у больных травматической болезнью при политравме.

Материалы и методы. Проспективное рандомизированное контролируемое клиническое исследование 120 пациентов было выполнено в отделении политравмы (Харьковская городская клиническая больница скорой и неотложной медицинской помощи им. проф. А. И. Мещанинова) после получения одобрения комиссии по биоэтике и информированного согласия пациентов.

Bce пострадавшие группы исследования доставлены в приемное отделение с

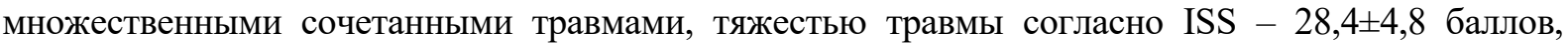
ВПХ-СП - 22,1 $\pm 3,5$ баллов, PTS - 21,3 $\pm 4,8$ баллов, кровопотерей $35,6 \pm 4,5 \%$ объема

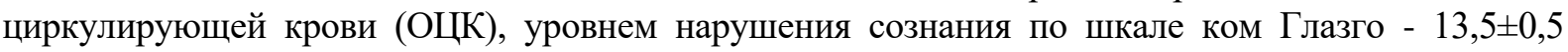

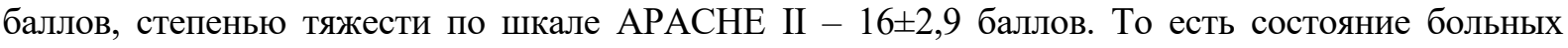
расценивалось как тяжелое нестабильное (согласно шкал ISS, RTS, BПХ-СП), с прогнозируемым максимальным уровнем летальности 33\% (согласно шкал ВПХ и TRISS, PTS, APACHE II) и уровнем ожидаемых осложнений $34 \%$ (ВПХ-СП). Кроме того, при поступлении в операционную у пациентов имелись признаки гиповолемии, что подтверждалось снижением среднего артериального давления (САД), тахикардией, снижением сердечного выброса (табл. 1). 
Таблица 1. Показатели кровообращения пациентов в остром периоде травматической болезни при политравме $(\mathrm{M} \pm \mathrm{m})$

\begin{tabular}{|l|c|}
\hline Показатель & $\mathbf{n = 1 2 0}$ \\
\hline САД, мм Нg & $61,2 \pm 4,2$ \\
\hline ЧСС, уд/мин. & $119,8 \pm 5,1$ \\
\hline ЦВД, мм $\mathrm{H}_{2} \mathrm{O}$ & $9,45 \pm 4,6$ \\
\hline УОС, мл & $42,5 \pm 4,9$ \\
\hline СИ, л/мин $/ \mathrm{m}^{2}$ & $2,17 \pm 0,34$ \\
\hline УИС, $\mathrm{мЛ} / \mathrm{m}^{2}$ & $25,1 \pm 2,6$ \\
\hline
\end{tabular}

ЧСС - частота сердечных сокращений; ЦВД - центральное венозное давление; УОС - ударный объем сердца; СИ - сердечный индекс, УИС - ударный индекс сердца.

Наличие множественной сочетанной травмы, тяжесть травмы и состояния пациентов обусловили то, что лечебный процесс был разделен на ряд этапов согласно принципу Damage control.

В соответствии с целями исследования в крови определяли основные маркеры функционального состояния эритроцитов - лактат, пируват, 2,3-ДФГ, АТФ спектрофотометрическим методом. Исследование проводилось на таких этапах - при поступлении в операционную, через 24 часа, на 3, 5 и 14 сутки.

Все исследования проводились в соответствии с Конвенцией Совета Европы «О защите прав человека и человеческого достоинства в связи с применением достижений биологии и медицины: Конвенция о правах человека и биомедицине (ETS № 164)» от 04.04.1997 г., и Хельсинкской декларации Всемирной медицинской ассоциации (2008 г.).

Цифровой материал обработан статистически с использованием t-критерия Стьюдента, используя корреляционный анализ провели поиск вероятных факторов, которые влияют на возможность развития осложнений.

Результаты и их обсуждение. В условиях централизации кровообращения на фоне гиповолемии ведущим звеном в патогенезе становится дефицит энергии, связанный с переходом метаболизма на энергетически менее выгодный анаэробный путь, что подтверждается повышением

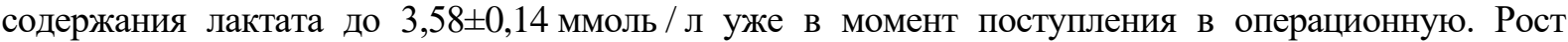
уровня лактата также является следствием гипоперфузии, в результате снижения среднего артериального давления у пациентов в состоянии травматического шока, повышения уровня катехоламинов в ответ на травму, нарушения процессов окислительного фосфорилирования и баланса между анаэробным и аэробным метаболизмом. Продолжающееся увеличение уровня лактата через 24 часа на $25 \%$ указывает на дальнейшее угнетение аэробного пути энергообразования. Но уже на 3-и сутки, доля аэробной продукции энергии возрастала и концентрация лактата достоверно $(\mathrm{p}<0,05)$ снижалась относительно предыдущей точки контроля на 18\%. Данная тенденция сохранялась до момента нормализации показателя на 14-е сутки (рис. 1).

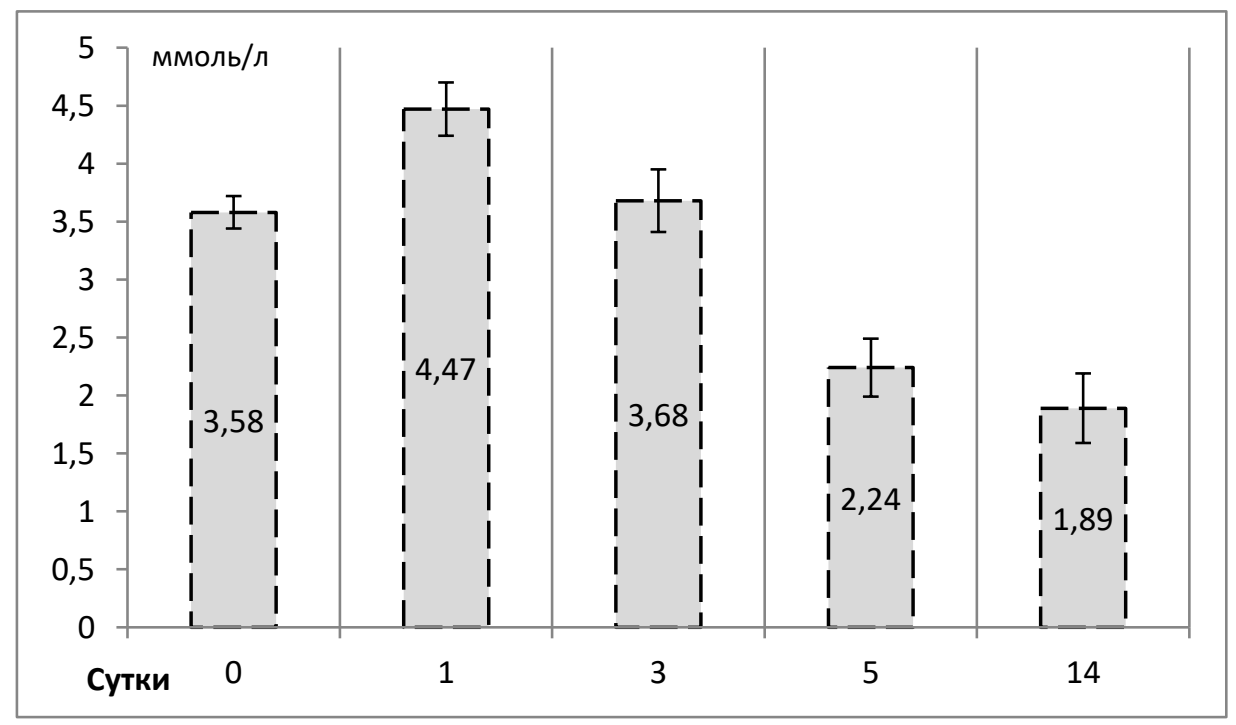

Рис. 1. Динамика уровня лактата 
Изначально высокие значения индекса лактат/пируват свидетельствовали о резком дисбалансе в соотношении доли гликолитического и окислительного превращения углеводов. Динамика индекса лактат/пируват была схожа с динамикой уровня лактата. Так через 24 часа данный индекс достигал своего максимального значения и был выше стартового уровня на $6,5 \%$. В дальнейшем за счет снижения лактатемии, нормализовалось значение индекса и уже на 14-е сутки можно говорить о возвращении баланса в соотношении аэробных и анаэробных метаболических процессов (рис. 2). Гипоперфузия и гипоксия приводят к клеточной дисфункции и смещению характера метаболизма в сторону анаэробного пути. В свою очередь гликолиз приводит к развитию лактат-ацидоза. В контексте колебаний концентрации основных маркеров ишемии и гипоксии (лактата и пирувата) можно судить о доставке и потреблении главного энергетического субстрата (глюкозы), а значит и об адекватности метаболизма жизненно важных органов $[11,12]$.

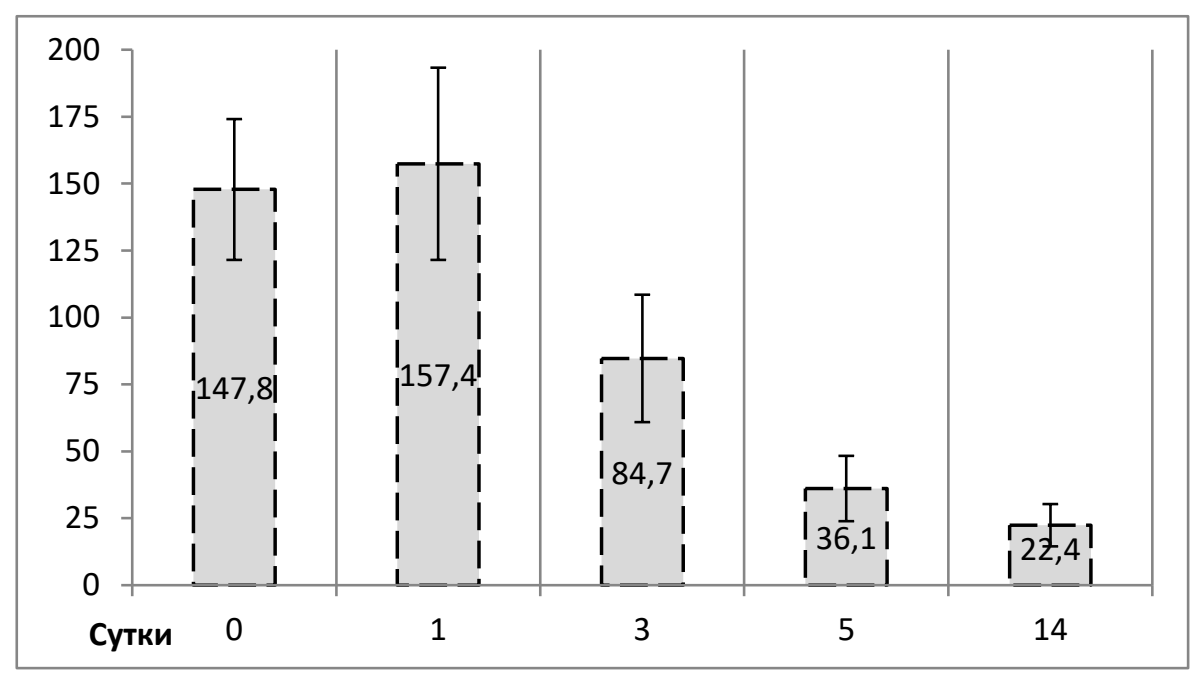

Рис. 2. Динамика уровня лактат/пируват

Также при анализе данных, полученных в ходе эксперимента, установлено достоверное повышение 2,3-ДФГ в эритроцитах пострадавших уже при поступлении в операционную (до $16,3 \pm 1,2$ ммоль/л), что более чем в 3 раза превышало допустимые нормативные значения. Указанное говорит о продолжении процессов активации анаэробного метаболизма. По нашему мнению, эти изменения свидетельствуют о повышении резервных возможностей системы транспорта кислорода и носят компенсаторный характер. К концу первых суток наблюдалось достоверное увеличение 2,3-ДФГ $(\mathrm{p}<0,05)$. Далее, на третий день ИТ, уровень 2,3 -ДФГ у больных оставался повышенным на $77 \%$ по сравнению со стартовым значением. Постепенное снижение до нормальных значений происходило с пятых по 14-е сутки (рис. 3).

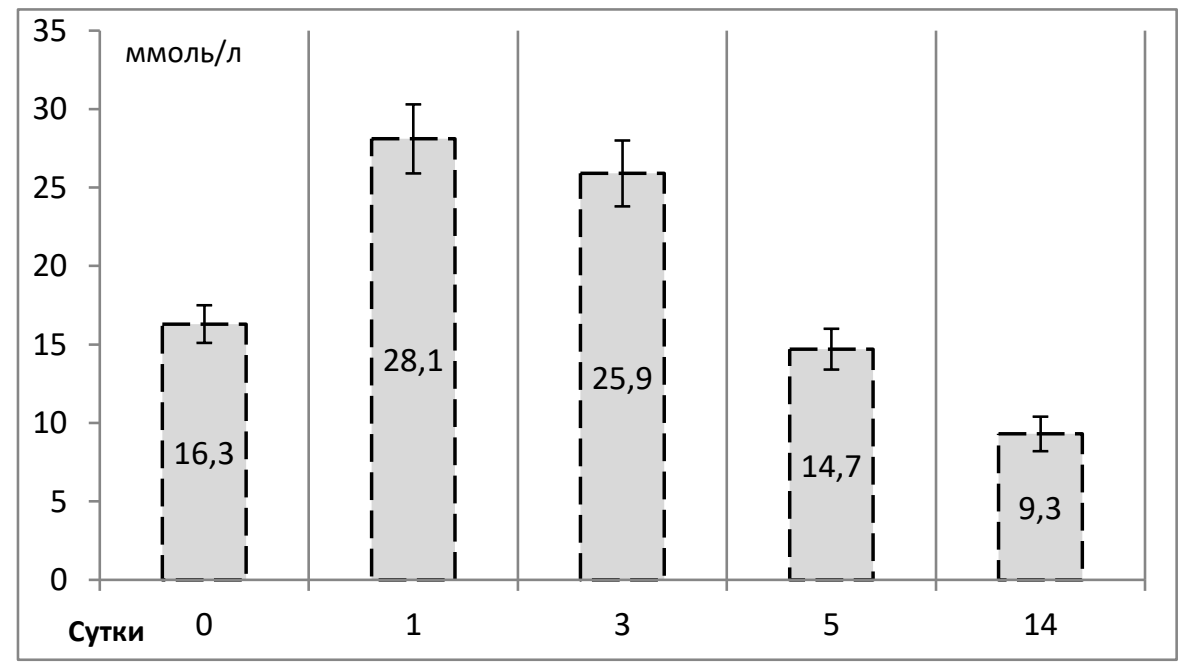

Рис. 3. Динамика уровня 2,3-ДФГ 


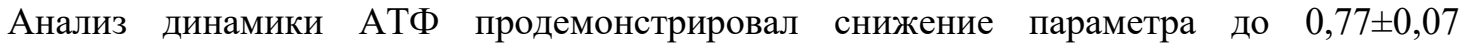
мкмоль/мл, причем в течение 24 часов после начала воздействия гипоксии концентрация АТФ продолжала снижение (на 16\%), как свидетельство нарушения митохондриальной выработки АТФ и ингибирования гликолитического пути освобождения энергии. Только с 3-х суток наметилась тенденция к постепенному росту и нормализации уровня АТФ (рис. 4).

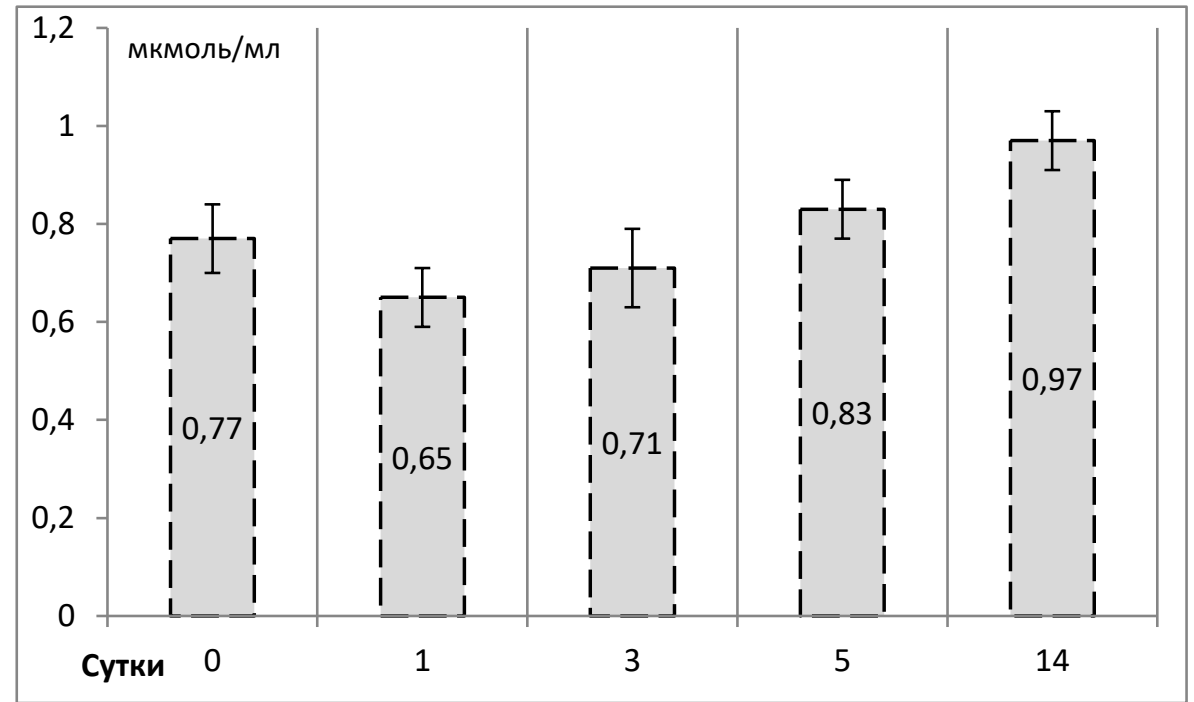

Рис. 4. Динамика уровня АТФ

Таким образом до 3-х суток сохраняется наибольшая напряженность компенсаторних механизмов, что подтверждает динамика изученных маркеров функционального состояния эритроцитов, причем максимальное напряжение резервныХ возможностей припадает на конец 1 -х суток с момента травмы.

В течение первых 2-х недель посттравматического периода были выявлены тяжелые осложнения: постгеморрагическая анемия - 92\%, посттравматическая нефропатия - 38\%, тромбогеморрагические - 29\%, и инфекционно-воспалительные осложнения $-51 \%$.

Таблица. 2. Результаты корреляционного анализа между показателями маркеров функционального состояния эритроцитов и развитием осложнений.

\begin{tabular}{|c|c|c|c|c|}
\hline \multirow[b]{2}{*}{ Вид осложнения } & \multicolumn{4}{|c|}{ Маркер } \\
\hline & Лактат & $\begin{array}{l}\text { Лактат/ } \\
\text { пируват }\end{array}$ & 2,3-ДФГ & АТФ \\
\hline Постгеморрагическая анемия & 0,658 & 0,572 & 0,721 & $-0,682$ \\
\hline Посттравматическая нефропатия & 0,634 & 0,496 & 0,328 & $-0,472$ \\
\hline Тромбогеморрагические осложнения & 0,161 & 0,232 & 0,496 & $-0,318$ \\
\hline Инфекционно-воспалительные осложнения & 0,898 & 0,652 & 0,864 & $-0,670$ \\
\hline
\end{tabular}

При проведении корреляционного анализа между показателями маркеров функционального состояния эритроцитов в момент поступления и развившимися осложнениями получены следующие результаты (табл. 2). Установлена, наиболее сильная связь между уровнем 2,3-ДФГ, АТФ и развитием инфекционно-воспалительных осложнений, постгеморрагической анемии, также между уровнем лактата; индексом лактат/пируват и развитием инфекционно-воспалительных осложнений, постгеморрагической анемии, посттравматической нефропатии.

Полученные показатели пациентов с ТБ при политравме свидетельствуют об изменениях, метаболических процессов в клетках. Исследуемые параметры принимают непосредственное участие в клеточном метаболизме кислорода. Нарушение обеспечения клетки кислородом является следствием изменений системного кровообращения, сопровождающих острую кровопотерю. Как известно, кислород - конечный акцептор электронов дыхательной цепи, 
поэтому дефицит его приводит к уменьшению транспорта электронов и протонов, а, следовательно, к несогласованности субстратного окисления и фосфорилирования. Это приводит к уменьшению энергетического потенциала в тканях, выражается снижением концентрации АТФ, то есть эффективность аэробного энергетического обмена снижается.

Результаты исследования демонстрируют необходимость продолжать его в данном направлении. Вероятно, имеет смысл применения в составе интенсивной терапии у пациентов с тяжелой сочетанной травмой препаратов, которые способствуют усилению компенсаторной активации аэробного гликолиза и снижению степени угнетения окислительных процессов в цикле Кребса в условиях гипоксии, в том числе способствуют увеличению содержания АТФ, что в результате приведет к улучшению качества лечения и снижению развития возможных осложнений.

Выводы. Течение острого и раннего периодов ТБ сопровождается изменениями функционального состояния эритроцитов, о чем свидетельствуют снижение уровня АТФ и увеличение уровней лактата, 2,3-ДФГ, индекса лактат/пируват в остром периоде.

Динамика изученных маркеров подтверждает развитие напряженности компенсаторных механизмов в эритроцитах в течение первых 3-х суток с момента травмы.

Найдена связь между маркерами функционального состояния эритроцитов в момент поступления и развитием инфекционно-воспалительных осложнений, постгеморрагической анемии, посттравматической нефропатии.

Расчеты показателей функционального состояния эритроцитов могут содержать дополнительную диагностическую и прогностическую информацию, которая позволит выявлять тенденции патологических изменений и качества лечения.

Перспективы дальнейших исследований. Изучение применения у пациентов с тяжелой сочетанной травмой в составе интенсивной терапии препаратов, которые оказывают влияние на метаболизм эритроцитов.

Конфликт интересов. Авторы заявляют об отсутствии конфликта интересов.

\section{ЛИТЕРАТУРА}

1. Scharfenberger A, Alabassi K, Smith S, Weber D, Dulai S, Bergman JW et al. Primary wound closure after open fracture: a prospective cohort study examining nonunion and deep infection. J. Orthop. Trauma. 2017; 31(3): 121-126. DOI: 10.1097/BOT.0000000000000751

2. Kempegowda H, Richard R, Borade A, Tawari A, Graham J, Suk M et al. Obesity is associated with high perioperative complications among surgically treated intertrochanteric fracture of the femur. J. Orthop. Trauma. 2017; 31(7): 352-357. DOI: 10.1097/BOT.0000000000000825

3. Прохоров А. В., Халимов Ю. Ш., Гайдук С. В., Гаврилин С. В., Мешаков Д. М., Чепель А. И. Современное состояние и перспективы диагностики нозокомиальной пневмонии у пострадавших при политравме. Вестник анестезиологии и реаниматологии. 2017; 14(5): 66-72. DOI: 10.21292/20785658-2017-14-5-66-72

4. Хромов А. А., Линник С. А. Инфекционные осложнения у больных с множественной и сочетанной травмой // Фундаментальные исследования. - 2015. - № 1. - С. 1245-1249.

5. Щеколова Н.Б., Ладейщиков В.М., Зубарева Н.С. Осложнения раннего периода травматической болезни при множественных повреждениях опорно-двигательной системы. Пермский медицинский журнал. 2016; XXXIII(3): 25-30. URL: https://fundamental-research.ru/pdf/2015/1-6/37752.pdf

6. Godat LN, Kobayashi L, Chang DC, Coimbra R. Can we ever stop worrying about venous thromboembolism after trauma? J Trauma Acute Care Surg. 2015; 78(3): 475-481. DOI: 10.1097/TA.0000000000000556

7. Pfeifer R, Pape HC. Diagnostics and treatment strategies for multiple trauma patients. Chirurg.2016; 87(2): 165-175. DOI: 10.1007/s00104-015-0139-0

8. Колмакова Т.С., Бойко Н.В., Быкова В.В., Смирнова О.Б. Изменения кислородтранспортной функции и энергетического обмена в эритроцитах у больных с носовыми кровотечениями. Кубанский научный медицинский вестник. 2017; 24(6): 71-77. DOI: 10.25207/1608-6228-2017-24-6-71-77

9. Perlman, R., Callum, J., Laflamme, C. et al. A recommended early goal-directed management guideline for the prevention of hypothermia-related transfusion, morbidity, and mortality in severely injured trauma patients. Crit Care. 2016; 20(1): 107. doi:10.1186/s13054-016-1271-z

10. Рябов Г. А. Гипоксия критических состояний / Г. А. Рябов. - М.: Медицина, 1988. -287 с.

11. Xu F, et al. Effect of hypoxia and hyperoxia on cerebral blood flow, blood oxygenation, and oxidative metabolism. J Cereb Blood Flow Metab 2012;32(10):1909-1918. DOI: 10.1038/jcbfm.2012.93 
12. Manikis P, Jankowski S, Zhang H, Kahn RJ, Vincent JL. Correlation of serial blood lactate levels to organ failure and mortality after trauma. Am J Emerg Med. 1995;13(6):619-22. DOI: 10.1016/07356757(95)90043-8

13. Jensen M L F, Vestergaard M B, Tønnesen P, Larsson H B W, Jennum Poul J. Cerebral blood flow, oxygen metabolism, and lactate during hypoxia in patients with obstructive sleep apnea. Sleep. - 2018. - V.41., Issue 3. P.1-10. https://doi.org/10.1093/sleep/zsy001

14. Дерюгина А. В., Бояринов Г. А., Симутис И. С., Бояринова Л. В., Азов Н. А. Морфологические и метаболические показатели эритроцитов при обработке озоном эритроцитной массы. GENERAL REANIMATOLOGY. 2018; 14(1): 40-49. DOI:10.15360/1813-9779-2018-1-40-49

15. Крылов В.Н., Дерюгина А.В., Симутис И.С., Бояринов Г.А., Сенюрина А.И. Содержание АТФ и 2,3ДФГ в эритроцитах при консервации и воздействии озона. Биомедицина. 2014; 2: 37-42. URL: http://scbmt.ru/mag/2014/2014-02.pdf\#page=39

16. Жегунов Г.Ф., Денисова О.Н., Землянских Н.Г. Криоконсервирование и сохранность эритроцитов животных. Проблемы криобиологии. 2005; 15(3): 566-569. URL: http://dspace.nbuv.gov.ua/bitstream/handle/123456789/138173/107-Zhegunov.pdf?sequence=1

17. Кукес В.Г., Горбач Т.В., Ромащенко О.В., Румбешт В.В., Закирова Л.Р., Алфёров П.К., Грищенко Н.Д., Стаценко Л.В., Горбунова Н.С., and Грищенко А.А. Аденозинтрифосфорная кислота в крови как маркер состояния энергетического обмена миокарда при оценке энергосберегающих эффектов метаболических корректоров. Научные ведомости БелГУ Серия: Медицина. Фармация. 2017; 26 (275): 185-196. URL: https://cyberleninka.ru/article/n/adenozintrifosfornaya-kislota-v-krovi-kak-markersostoyaniya-energeticheskogo-obmena-miokarda-pri-otsenke-energosberegayuschih 